\title{
Democracia sin compromiso en la República Dominicana y Ecuador *
}

\author{
Catherine M. Conaghan** \\ Rosario Espinal \\ QUEEN'S UNIVERSTTY, TORONTO \\ TEMPLE UNIVERSTTY, FILADELFIA
}

\section{INTRODUCCIÓN}

$\mathrm{D}$

elinear las rutas históricas hacia la democracia ha sido una vieja preocupación de la sociología política ${ }^{1}$ Con la desaparición de los gobiernos autoritarios en América Latina a lo largo de la década pasada, ha resurgido una pregunta clásica de la disciplina: iexisten ciertas secuencias de desarrollo que producen con mayor probabilidad transiciones exitosas hacia la democracia? Si se puede llegar a alguna conclusión a partir de las experiencias recientes, la respuesta es no. Circunstancias bastante heterogéneas produjeron la ola más reciente de

* Publicado en Journal of Latin American Studies, Cambridge University Press, vol. xxil, núm. 3, octubre de 1990, pp. 553-574. Traducción de Johanna von Grafenstein.

** Queremos agradecer al Instituto Helen Kellog y a la Universidad de Notre Dame su apoyo y a Guillermo O'Donell su orientación.

i El trabajo clásico sobre el tema es Moore, Jr., Social origins, 1966. En la misma línea de acercamiento macrohistórico de Moore véase la discusión sobre Francia en Skocpol, State and social, 1979. Véase también la discusión sobre secuencias históricas en la democratización en Dahl, Polyarclyy, 1971. 
democratización. Desde el Caribe hasta el Cono Sur, paises de diferentes niveles de desarrollo económico, con herencias autoritarias distintas y diversas estructuras de clase, todos realizaron transiciones hacia gobiernos civiles, electos durante la última década.

A la luz de este hecho, hay que formular una pregunta diferente: iexactamente qué tipo de democracias emergieron de estas circunstancias y procesos de transición diversos? Mientras que el movimiento hacia gobiernos popularmente electos ha sido una tendencia general en la región en años recientes, existen variaciones significativas entre esos países en cuanto hasta qué punto prácticas democráticas "normales" estructuran el comportamiento de actores-clave. ${ }^{2}$ Para comprender estas variaciones en las prácticas democráticas y sus efectos sobre el carácter de estos regímenes, es necesario el estudio comparativo. En particular, necesitamos examinar la interacción compleja de estructuras de clase y estado y cómo éstas definen los parámetros dentro de los cuales se lleva a cabo la democratización.

La República Dominicana y Ecuador son casos importantes para el análisis de un desarrollo democrático en América Latina, por lo menos por dos razones. En primer lugar, porque eran democratizadores improbables. En contraste con las democracias capitalistas avanzadas o con los países más industrializados de América Latina, la transición democrática en los dos casos se llevó a cabo en condiciones socioestructurales adversas. ${ }^{3}$ Estas condiciones socioestructurales se pueden resumir de la siguiente manera: 1) La historia política de ambos países está marcada por una extrema desorganización de la sociedad civil. 2) Las elites conservadoras dominaban regímenes políticos excluyentes que, por mucho, no conocían desafio alguno de los sectores populares, en alto grado oprimidos y desmovilizados. 3) Sus economías eran en gran parte dependientes de las exportaciones agrícolas, con una presencia significativa del capital foráneo en la República Dominicana. 4) La diferenciación socioestructural estaba retardada por una industrialización tardía, incluso para los estándares latinoamericanos. 5) Las clases medias reformistas, las clases trabajadoras militantes y una burguesía políticamente flexible (que había sido el soporte para el establecimiento de la democracia liberal en

2 La noción de "normalidad" y "anormalidad" en un régimen se tomó de la discusión de O'Donell, y Schmitter, Transitions, 1988, p. 65. Ellos definen "normalidad" como una situación en la que "los actores han instituido y obedecen a un conjunto de reglas más o menos explícitas que definen los canales que pueden usar para acceder a puestos de gobierno, los medios que legítimamente pueden emplear en sus conflictos, los procedimientos a que deberían recurrir al tomar decisiones y los criterios que pueden usar para excluir a otros del juego".

${ }^{3}$ Guillermo O'Donell observa el carácter excepcional de las transiciones dominicana y ecuatoriana, véase al respecto su "Introduction to the Latin American cases", en O'Donell, Schmitter y Whitehead (comps.), Transitions, 1986, p. 5. 


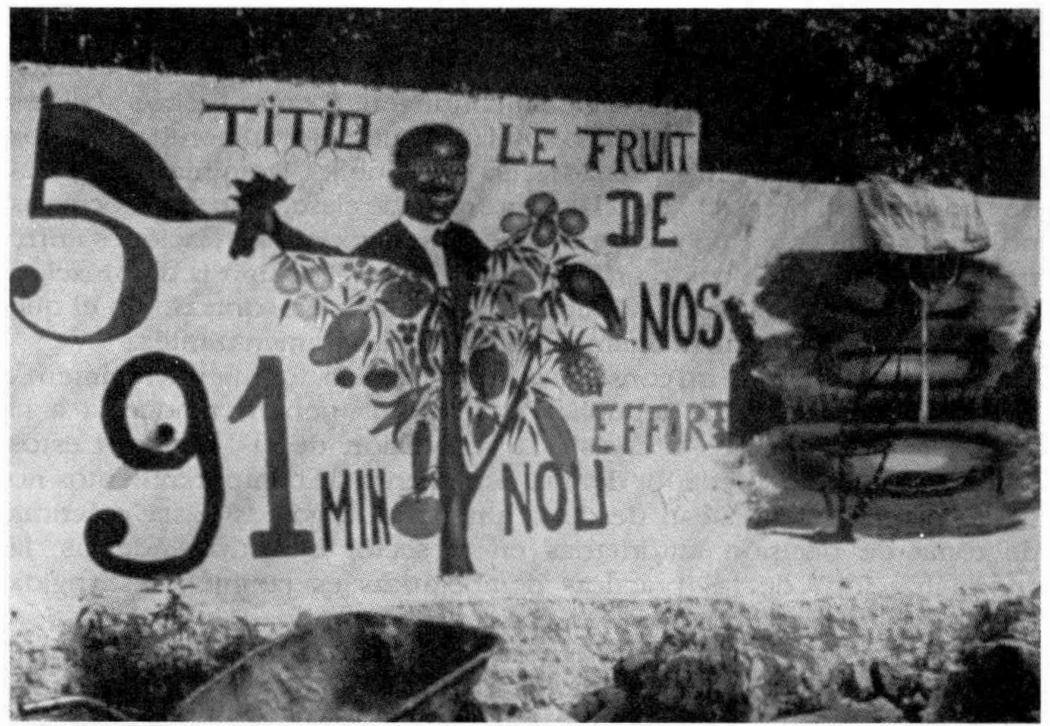

Europa Occidental y de los regímenes populistas del Cono Sur) eran débiles o ausentes en estos casos. A causa de la adversas condiciones socioestructurales prevalecientes, las transiciones de la Dominicana y Ecuador son probablemente más relevantes para otros países con industrialización muy tardía que las lecciones del Cono Sur, donde la industrialización más temprana y el populismo produjeron actores históricos diferentes y oportunidades políticas alternativas.

En segundo lugar, la República Dominicana y Ecuador fueron los líderes cronológicos de la reciente ola de transiciones democráticas en América Latina (en 1978 y 1979, respectivamente). Como tales nos proveen un marco temporal más largo para analizar el desarrollo político postransicional. Ambos países han conocido más de una elección nacional desde la transición y han experimentado la transferencia de poder a partidos de oposición.

El argumento central de este trabajo es que las estructuras socioeconómicas y el legado político del periodo autoritario anterior produjeron un tipo de régimen "democrático-autoritario" híbrido en la República Dominicana y el Ecuador. Un régimen de este tipo se caracteriza por una competencia política abierta y elecciones libres, pero esto se combina con violaciones episódicas de los procedimientos democráticos y con un com- 
promiso limitado con respecto a las normas democráticas entre las elites económicas y políticas. En contraste con el argumento de Adam Przeworski de que la democracia liberal en sistemas capitalistas avanza. dos es un "compromiso institucional contingente" entre fuerzas sociales basado en un proyecto económico keysiano, nuestro argumento es que los regimenes recientemente instalados en la República Dominicana y Ecuador no han sido producto de tal compromiso de clase. ${ }^{4}$ Estas democracias no emergieron como un pacto político para negociar las relaciones entre trabajo y capital, sino como un vehículo para reestructurar la dominación detentada por las elites económicas y políticas en un contexto en el que las clases bajas no estaban altamente movilizadas y amenazantes.

A causa de la falta de un consenso social y político, los nuevos regímenes civiles en Ecuador y la República Dominicana tienen "tendencia a la crisis", son "propensos a crisis". La resolución de las crisis en estos sistemas ha girado alrededor del mantenimiento de comportamientos no democráticos que abarcan desde la amenaza de golpes hasta prácticas de toma de decisión autoritarias en el sector ejecutivo. Además, la "normalización" de las prácticas democráticas es también restringida porque las crisis económicas son cosa corriente. Aunado a la limitación de los recursos económicos del Estado, el manejo del problema de la deuda internacional crea en los políticos el impulso de aislar la toma de decisiones sobre política económica de las presiones sociales; frecuentemente estas discusiones no entran a debate en el Congreso, debilitándose así la legislatura como cuerpo que debe intervenir realmente en la política. Otra característica llamativa de estos sistemas políticos es la extendida falta de responsabilidad: entre el gobierno y los partidos, entre los legisladores y los partidos, entre los partidos y las masas. Eso se evidencia en una amplia gama de fenómenos, desde los virajes vertiginosos en las alianzas partidarias hasta el abandono de objetivos de redistribución y participación por los partidos "progresistas". Pero para comprender el carácter contradictorio de estos regímenes políticos nuevos, tenemos que examinar primeramente las condiciones históricas que los produjeron.

\section{ESTADO Y SOCIEDAD CIVIL: LA ORGANIZACIÓN DE LA EXCLUSIÓN}

Hasta su transición reciente, la República Dominicana y Ecuador eran sistemas políticos altamente excluyentes. La durabilidad de las concepciones dictatoriales y oligárquicas de la política, los tradicionalmente bajos nive. les de participación política de las clases bajas y la relativa "tardanza" de la

\footnotetext{
4 La idea de democracia como compromiso de clase es desarrollada en numerosos trabajos por Adam Przeworski. Véase, por ejemplo, Adam Przeworski y Michael Wallerstein, "The structure of class", American Political, 1982; véase también la colección de ensayos de Przeworski, Capitalism, 1985.
} 
democratización eran parte del legado de sus economías de exportación. ${ }^{5}$

La integración de Ecuador al mercado internacional a finales del siglo XIX produjo una estructura de clase heterogénea y fragmentada. En la punta de la pirámide social se encontraban dos grupos de elites regionales que se diferenciaban por sus intereses económicos. La costa estaba dominada por una burguesía agrofinanciera del puerto de Guayaquil que controlaba el comercio de la coca. En el interior montañoso o sierra, una clase terrateniente tradicional mantenía un sistema de haciendas que producía para el mercado interior. Los conflictos entre estas elites regionales por el control del estado se expresaban en la competencia electoral entre los Partidos Liberal y Conservador, pero también desembocaban en tomas de poder no electorales. No obstante las serias tensiones entre estos grupos, no había contradicciones económicas profundas entre los dos y ningún grupo llegó jamás a usar el control del Estado para desmantelar la base económica de su rival.

La integración de la República Dominicana al mercado internacional alrededor de 1900 fue el resultado de la expansión de las inversiones extranjeras directas de los Estados Unidos en el Caribe. En contraste con el Ecuador, donde una oligarquía local desempeñó un papel central en la organización del sector de exportación y en la conservación del orden político, la elite tradicional dominicana no controlaba la industria azucarera. Con la ocupación militar estadunidense de 1916-24, no sólo la economía azucarera cayó bajo el control del capital extranjero, sino también el Estado que fue dominado por una potencia externa. Como en otros países del Caribe y Centroamérica, la burguesía local embrionaria se vería políticamente derrotada y económicamente marginalizada en los años 20. Dictaduras militares subsecuentes como la del general Rafael Leónidas Trujillo (1931-61) se establecieron como un sustituto nacional a la dominación extranjera directa.

En contraste con la República Dominicana, donde la dependencia externa y los conflictos internos llevaron al eclipse de las elites civiles y a la instauración de una dictadura militar personalista, una mayor autonomía y capacidad de acomodación de las clases dominantes ecuatorianas dejaba espacio para el desarrollo de un sistema electoral oligárquico que permitía la rotación del poder. El electorado no oligárquico. ecuatoriano era competitivo en relación a los partidos, pero restrictivo con respecto al sufragio, esto es, el sistema de partidos era abierto con la participación de izquierdistas y populistas, mientras que el registro y los requerimientos de saber leer y escribir restringían severamente la extensión y la

${ }^{5}$ El repaso del desarrollo histórico de estos países se basa en nuestro trabajo previo. Para una discusión más detallada sobre el caso dominicano, véase Rosario Espinal, Autoritarismo, 1987. Véase también Espinal. "Clases", 1985. Sobre Ecuador, véase Conaghan, Restructuring, 1988. 
composición de clase de electorado hasta los cambios constitucionales de 1978. En cambio, bajo el sistema político dominicano maquinado por Trujillo, la dominación de un partido único impedía la competencia de partidos aun cuando en los cuarenta no había restricciones al sufragio. Trujillo creó un vehículo electoral -el Partido Dominicano- usándolo periódicamente para legitimar su poder. Mantuvo un control personal extensivo tanto de la política como de la economía; las elecciones sólo tenían como fin organizar a la población en apoyo a la dictadura.

El apogeo del electoralismo de Ecuador se dio durante el "paréntesis democrático" entre 1948 y 1961, cuando la presidencia se transfirió pacíficamente entre los partidos tradicionales. La evolución del sistema de partidos reflejaba el carácter del electorado restringido; existían los partidos tradicionales Liberales y Conservadores, junto con los de los grupos que se desprendieron de esos partidos. Iniciado en los treinta, el descontento popular se canalizaba a través de un populismo altamente conservador y cooptador practicado por José María Velasco Ibarra. No obstante su retórica populista, Velasco mantuvo vínculos estrechos con las elites tradicionales y no emprendió ningún programa redistributivo durante sus cinco periodos presidenciales. Un nuevo partido populista emergió en los cuarenta, la Concentración de Fuerzas Populares (CFP), pero su crecimiento fue limitado por su identificación como un partido regional de Guayaquil.

Por la ausencia de demandas concertadas desde abajo, la presión para cambiar el electoralismo oligárquico en el Ecuador fue limitada. Los arreglos corporativistas permeaban el tejido del sistema político; la representación de los intereses corporativos se efectuaba por conducto de las asociaciones nacionales de productores, las cámaras de Comercio, Industria y Agricultura. Además de reservarse puestos en los consejos directivos del gobierno, estas organizaciones empresariales ostentaban nombramientos de "senadores funcionales" en la legislatura nacional.

De los años treinta a los cincuenta, el sistema oligárquico en Ecuador y el régimen dictatorial en la República Dominicana bloquearon la incorporación de las clases subordinadas. Las clases medias y trabajadoras permanecieron numéricamente pequeñas durante este periodo, debido a los limitados efectos desencadenadores de la agricultura tropical de exportación. El grueso de la mano de obra permaneció en el agro, trabajando en una variedad de lugáres. La mano de obra rural se componía de campesinos, asalariados y pequeños rancheros capitalistas. En Ecuador, las relaciones capitalistas de producción dominaban en la agricultura de exportación de la costa, mientras que persistian relaciones precapitalistas en el sistema de hacienda de la sierra hasta los años sesenta. El carácter heterogéneo de la mano de obra rural era agravado por las diferencias étnicas, lingüisticas y culturales entre las poblaciones costera y serrana y por las divisiones dentro de los grupos indígenas del interior. En 
la República Dominicana el empleo de trabajadores negros de Haití y del Caribe anglófono en la industria azucarera, creaba un proletariado linguística y étnicamente diverso, lo que dificultaba su organización. En el resto de la economía agrícola muchos campesinos y pequeños propietarios eran dominicanos de habla castellana.

Dadas las estructuras sociales fragmentadas y el carácter excluyente de los regímenes políticos, el crecimiento de las organizaciones de clase populares y de los partidos políticos de masas fue en gran medida frenado en ambos países. El sindicalismo era débil. En 1942, Trujillo legalizó la Confederación Dominicana del Trabajo (CDr) que se convirtió en una organización cooptada sin apoyo de base. Las huelgas organizadas por los obreros del azúcar a mediados de los cuarenta para mejorar las condiciones de trabajo, lograron algunas concesiones, pero el movimiento fue aplastado por el gobierno. Los líderes obreros fueron asesinados o forzados a salir al exilio. La tradición de represión laboral en Ecuador se inició en 1922 cuando cientos de trabajadores murieron en una confrontación con tropas gubernamentales durante una huelga general en Guayaquil. Además, algunos conflictos políticos y económicos fragmentaron al movimiento laboral y se crearon tres sindicatos que competian entre si. ${ }^{6}$

En los años sesenta, las trasformaciones socioeconómicas estaban en camino en ambos países. En Ecuador, el cambio hacia la exportación del plátano en la costa conllevaba el crecimiento económico y la expansión de propiedades medianas. En la sierra, terratenientes emprendedores empezaron a adoptar métodos más intensivos en inversión de capitales y se convirtieron en defensores de una reforma agraria limitada para desembarazarse de sus obligaciones tradicionales con los inquilinos arrendatarios. Al mismo tiempo, el gobierno nacional adoptó políticas en favor de la sustitución de importaciones lo que sentó las bases para la industrialización. La modernización económica de la posguerra trajo consigo una expansión de las clases medias y trabajadoras urbanas, conjuntamente con modificaiones en la estructura de intereses de las clases dominantes, ya que los capitales se movían hacía la inversión industrial. En la República Dominicana, el excedente económico generado por el boom azucarero de los cuarenta fue monopolizado por Trujillo quien usaba su poder político para amasar una fortuna personal en tierras y en industria. Pero aun bajo esas circunstancias, la introducción de la industrialización para la sustitución de importaciones, trajo consigo alguna expansión en el tamaño de las clases medias y trabajadoras urbanas. Éstas, concentradas en las áreas urbanas, desempeñaron un papel importante en la caída de la dictadura en 1961 y en los años posteriores.

${ }^{6}$ Para una discusión de esta fragmentación en el temprano movimiento de unión, véase Middleton, "División", Journal, 1982. 
El estado cambiante de dichas clases se reflejó en el desarrollo de nuevas organizaciones y de discursos ideológicos frescos, en los tempranos sesenta.

Hacia finales de esa década la fragmentación de los tradicionales partidos Liberal y Conservador produjo en Ecuador los partidos Demócratacristiano y Socialdemócrata y nuevas agrupaciones personalistas; al mismo tiempo, el apoyo electoral al CFP populista creció. Con estos nuevos actores en la escena, populismo y desarrollismo se convirtieron en temas clave de la política nacional. El electoralismo oligárquico se mostró incapaz de adaptarse a esta estructura cambiante de intereses, demandas y discursos, lo que abrió las puertas a la inestabilidad política. La mala administración pública de los civiles y la recesión económica provocaron una intervención militar en 1963 a la que siguió un gobierno civil interino y el último esfuerzo por restaurar el electoralismo oligárquico en 1968. Este intervalo terminó con la proclamaciónn de una dictadura civil en 1970 por el presidente Velasco Ibarra a la que siguió una intervención militar en 1972.

En la Dominicana al terminar la década de los cincuenta, él fracaso de Trujillo de lograr el apoyo de los nuevos grupos sociales llevó a su creciente aislamiento y eventual asesinato en 1961. Al colapso de la dictadura siguió un nuevo florecimiento de la sociedad civil que se reflejó en la organización de partidos políticos, sindicatos y asociaciones profesionales y empresariales. Como en Ecuador, los actores recientemente organizados articularon demandas de redistribución y desarrollo. La organización política más importante de este tipo era el Partido Revolucionario Dominicano (PRD) de centro-izquierda, dirigido por el abiertamente nacionalista Juan Bosch. Fundado desde afuera por exiliados al principio de los cuarenta, el PRD pudo organizarse libremente en 1961 y ganó el apoyo de una base suficientemente amplia para ganar las elecciones nacionales de 1962. Por temor al discurso nacionalista, reformista y ateo del PRD, las elites empresariales y la Iglesia apoyaron un golpe militar que derrocó a Bosch en septiembre de $1963 .{ }^{7}$ Una junta civil interina sucedió al golpe, pero se mostró incapaz de contener las demandas y movilización sociales. La creciente movilización y polarización llevó a una guerra civil en 1965 que fue aplastada inmediatamente por una intervención militar directa de Estados Unidos. Las convulsiones acabaron en la restauración de un gobierno autoritario bajo nuevo ropaje. Las elecciones de "demostración" de 1966, supervisadas por Estados Unidos, llevaron al poder a Joaquín Balaguer, un antiguo aliado de Trujillo. ${ }^{8}$

7 Para una discusión detallada de estos sucesos, véase Gleijeses, The Dominican, 1978.

8 Para una discusión de "elecciones de demostración" véase Herman y Broadhead, Demostration elections, 1984. 
Tanto en la República Dominicana como en Ecuador, la inestabilidad de los años sesenta era consecuencia de las transformaciones socioeconómicas y de la incapacidad de las elites tradicionales -largo tiempo acostumbradas a la política de exclusión- de cambiar sus fórmụlas de-gobierno para incorporar nuevos grupos a la vida política. De esta manera, golpes militares, revueltas sociales y gobiernos provisionales eran las respuestas ad boc al colapso del viejo régimen. En última instancia, la fórmula que emergió como una solución a la desintegración del viejo orden no fue una democracia liberal sino un autoritarismo restaurado que se dio en su expresión militar en Ecuador y civil en la República Dominicana. Los regímenes autoritarios inaugurados en 1966 en la República Dominicana y en 1972 en Ecuador, buscaron cooptar a las clases dominantes y a las clases medias a través de su política económica, mientras mantenían el control sobre la participación política, especialmente de las clases bajas.

EL AUTORITARISMO DE LOS SETENTA: PREPARANDO EL ESCENARIO DE LA TRANSICIÓN

La observación de Gramsci de que una crisis es una situación en la que "lo viejo está muriendo y lo nuevo no logra nacer", describe adecuadamente las circunstancias bajo las cuales fueron instalados los

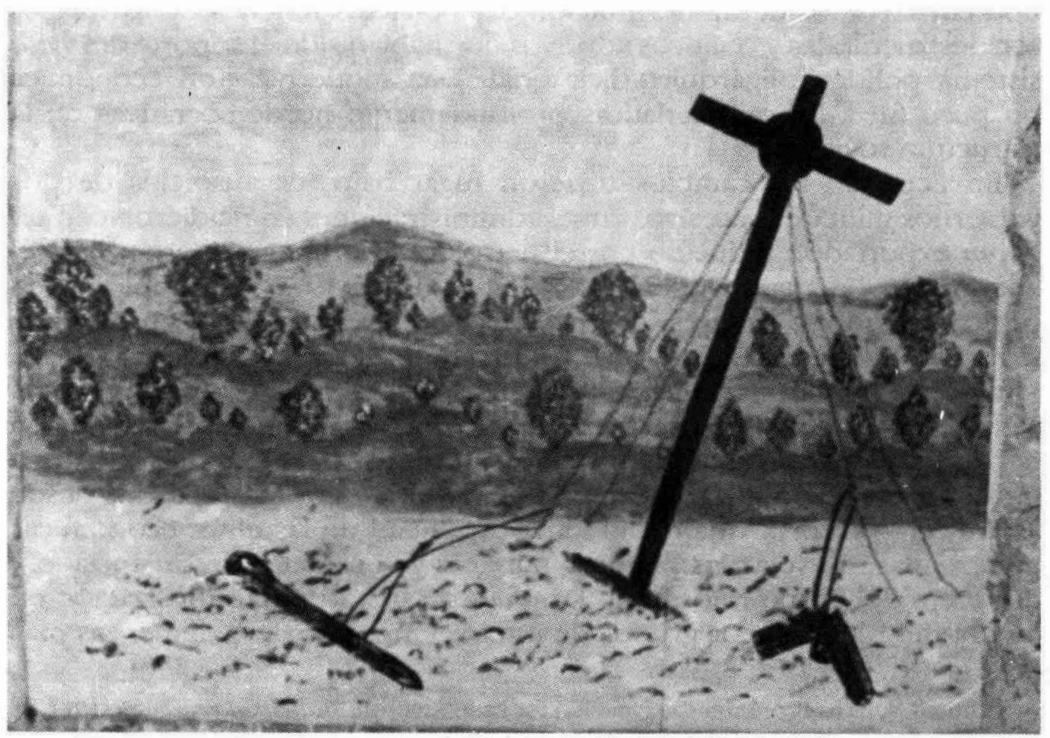


regímenes autoritarios en la República Dominicana y Ecuador y el legado político que dejaron atrás. Más que superar el conflicto entre la política de viejo estilo y las nuevas realidades sociales, estos gobiernos emprendieron políticas contradictorias que conservaban un espacio para los detentores tradicionales de poder pero que generaban un contexto para la transición de régimen.

Los regímenes autoritarios recientemente instalados, sobre una base militar en el Ecuador (1972-79) y otra civil en la República Dominicana (1966-78) eran modernizadores económicos. Emprendieron políticas que incrementaron el tamaño del estado en su conjunto, desarrollaron la infraestructura y promovieron la diversificación económica, cánalizando al efecto el crédito y la inversión pública. Conjuntamente con Brasil, Ecuador y la República Dominicana mostraron los índices más altos de crecimiento manufacturero en América Latina durante el periodo 197075.9 Pero aun si estos regímenes encabezaron importantes cambios en el papel del estado y de la estructura de la economía, no sometieron a la sociedad a una reestructuración fundamental de las relaciones de poder. No hicieron nada para fortalecer la capacidad de organización y movilización de las clases bajas, ni minaron las bases económicas de poder de las elites empresariales existentes. En el fondo, el espectro de la organización política fue prácticamente "congelado" ya que los partidos y organizaciones existentes se vieron limitados en sus actividades. Este tipo conservador de modernización dejó intactos muchos de los rasgos socioestructurales y políticos adversos que habían sido el soporte del viejo sistema político oligárquico/dictatorial. Esta modernización económica no puso fin a las características profundamente no democráticas de la estructura social.

En Ecuador, los cambios tuvieron lugar bajo los auspicios de dos gobiernos militares sucesivos cuyas administraciones coincidieron con un boom exportador, inducido por el petróleo. El primer gobierno, bajo el liderazgo del general Guillermo Rodríguez Lara (1972-70) adoptó en un principio un tono progresista y nacionalista, imitando de alguna manera la retórica del régimen reformista del vecino Perú bajo el general Velasco Alvarado. Las reformas iniciales, propuestas por los tecnócratas militares y civiles del equipo de Rodríguez de Lara, incluían una mayor regulación del capital extranjero y de las prácticas empresariales del capital local y una muy limitada reforma agraria. Pero este tímido intento de "reforma desde arriba" era de corta vida debido a la capacidad de las elites económicas organizadas, de vetar las políticas públicas y al carácter desorganizado y disparejo del grupo reformista. Después de una intensa movilización en contra del régimen por grupos de interés empresariales, elementos más 107.

9 United Nations Economic Commission for Latin America, Statistical yearbook, 1981, p. 
conservadores de las fuerzas armadas destituyeron a Rodríguez de Lara en 1976. La junta militar subsecuente, encabezada por el almirante Poveda Burbano, canceló del todo la agenda reformista (1976-79).

La modernización conservadora, que se dio en la República Dominicana bajo el presidente Joaquín Balaguer (1966-78), si bien no se puede entender como un proceso completamente paralelo, comparte algunas características con la experiencia ecuatoriana. La más significativa es que la administración de Balaguer implementó una política de crecimiento económico, en tanto que mantuvo excluidos a los sectores populares de la toma de decisiones políticas. Durante el boom económico de finales de los sesenta y principios de los setenta los salarios fueron congelados y los campesinos se vieron forzados a subsidiar la expansión urbana a través del control de precios impuesto por el gobierno a los productos agrícolas. La única medida tenuemente populista del régimen de Balaguer fue una reforma agraria limitada, puesta en marcha en 1972 y diseñada antes que nada para promover el crecimiento urbano-industrial. El gobierno mantuvo bajos los precios de los productos agrícolas, alentando a los grandes propietarios a vender sus tierras y a diversificar sus inversiones.

El papel de Ecuador como importante exportador de petróleo y los altos precios del azúcar dominicano conllevaron un crecimiento económico y una expansión de los ingresos públicos sin precedente durante los setenta; y además, el proceso de industrialización para la sustitución de importaciones que se alimentó con la canalización de créditos y subsidios al sector privado. Un éxodo campesino a las ciudades contribuyó al crecimiento del sector informal, mientras el tamaño de la clase obrera permaneció estático, debido al carácter intensivo de capitalización de la nueva industria. Se aceleró la diferenciación social dado que la expansión del empleo en servicios de los sectores privado y público acrecentaba las filas de las clases medias. Los intereses de las clases dominantes también se hicieron más heterogéneos ya que los grupos económicos diversificaron su clientela. En resumen, los procesos de cambio social que se iniciaron durante el boom de la exportación en los años cuarenta y cincuenta se aceleraron con la bonanza de la exportación de los setenta.

Sin embargo, es importante recordar que estos cambios económicos y la proliferación de "intereses" asociada a ellos, se dieron en un contexto que limitaba los reclamos y necesidades de la sociedad civil. Los canales para representar los intereses sociales no eran muy desarrollados ni incluyentes. En Ecuador, las asociaciones más efectivas eran las que representaban intereses económicos (por ejemplo las Cámaras de Comercio, Industria etc.). Los vehículos organizativos para representar los intereses de las grandes mayorías eran o embrionarias (por ejemplo los partidos modernos como los demócrata-cristianos o los socialdemócratas) o concentrados en una pequeña parte de la población (como en el caso 
de los sindicatos). Además la "crisis de representación" en la sociedad ecuatoriana se agravó porque los militares suspendieron los canales normales de representación de intereses. Rodríguez de Lara interrumpió la representación formal de grupos al suspender el Congreso, prohibiendo la actividad partidista y excluyendo a los grupos corporativos de los cuerpos directivos. Las consultas esporádicas a grupos e individuos reemplazaron a la representación institucional.

En la República Dominicana los canales de representación fueron también interrumpidos por el autoritarismo civil de Balaguer. Aunque Balaguer no cerró el Congreso, éste operaba completamente subordinado al poder ejecutivo. El gobierno no prohibió oficialmente los partidos políticos (con excepción de las organizaciones marxistas), pero limitó la vida partidaria por medio de las tácticas represivas de las agencias gubernamentales y de las fuerzas paramilitares. Como en el Ecuador, en la República Dominicana, Balaguer recurrió a consultar a contados individuos para reemplazar la toma de decisiones institucionalizada.

En ambos casos, la falta de mecanismos para la representación de intereses y de contacto predecible con funcionarios públicos se tornó crecientemente problemática para la burguesía a mediados de los setenta. En Ecuador, la burguesía empresarial vio la suspensión de su participación directa en las deliberaciones de política económica como una usurpación de su derecho tradicional a ser oída en estos asuntos. En la República Dominicana, la estrategia de Balaguer, de incorporar selectivamente hombres de negocios a consejos consultivos y agencias gubernamentales, alejó a los nuevos empresarios que quedaron fuera de estos acuerdos muy personalizados. De esta manera, mientras que la política económica en su conjunto era favorable al sector privado, la falta de mecanismos para integrar una gama amplia de grupos empresariales alejó a muchos del gobierno y los impulsó hacia la oposición.

En Ecuador, la presencia de una burguesía relativamente organizada y políticamente desinteresada que operaba al margen de las clases bajas organizadas y movilizadas, fue suficiente para socavar aun las modestas reformas propuestas por los tecnócratas militares y civiles y para crear de hecho una dinámica para la reinstalación de un gobierno civil en 1976. Como el régimen de Rodríguez de Lara había impedido la movilización popular, no existía ya ningún grupo organizado que pudiera actuar como contrapeso del grupo de presión antirreformista que representaba a la burguesía y que se concentraba en las cámaras de Agricultura, Industria y Comercio. Dichas cámaras utilizaban los medios de comunicación y actuaban a través de foros y encuentros para dirigir sus ataques, siempre consistentes y efectivos, virtualmente a todas las reformas propuestas por el gobierno. En sus ataques, los portavoces de las cámaras no se quejaban simplemente del contenido de las medidas económicas, sino que criticaban seriamente la falta de participación del sector empresarial 
en la formulación de las medidas. Esta crítica se convirtió en la base de sus llamados a un retorno constitucional. Los ataques mencionados alcanzaron un punto álgido en agosto de 1975 cuando las Cámaras reaccionaron fuertemente ante las medidas de austeridad instauradas por el gobierno. Los partidos de derecha se unieron al sector empresarial para pedir el cese del mismo. En enero de 1976, Rodríguez de Lara fue depuesto y las fuerzas armadas anunciaron su intención de reinstalar un gobierno civil.

En la República Dominicana, el apoyo de la burguesía a la democracia no apareció claramente antes de las elecciones de 1978. Hasta bien entrados los setenta, la burguesía había seguido en gran medida el proyecto de Balaguer para la modernización y el crecimiento, obteniendo poca autonomía del gobierno. Se hicieron evidentes signos de descontento en 1976, pero las tensiones fueron hábilmente contenidas en un marco de diálogo entre los representantes del sector empresarial y el gobierno. A la exigencia, por parte de los grupos empresariales, de una mayor participación en el proceso de decisiones, Balaguı:r contestó con un llamado a mantener reuniones regulares en el palar.io nacional. Esto ayudó a pacificar a las elites empresariales, y a difere? cia de la experiencia ecuatoriana, el colapso del régimen de Balaguf.r no fue precedido por una confrontación abierta entre gobierno y sector empresarial. Los empresarios se subieron al carro de la democratización cuando la popularidad del PRD creció entre los sectores urbanos de las clases medias y bajas. Pero el apoyo de la burguesía a la democracia sólo se hizo explícito en la noche del 17 de mayo de 1978 cuando prominentes líderes empresariales rechazaron el intento de golpe, encabezado por una pequeña facción militar en pro de Balaguer.

El declive del apoyo al autoritarismo en la sociedad dominicana, aun entre los detentores del poder económico, preparó el terreno para una transición política. Como el gobierno de Balaguer había mantenido una fachada formalmente institucional (existencia de partidos políticos, del Congreso, de una constitución "democrática"), los dominicanos podían evitarse debates prolongados sobre cómo estructurar un marco legal para la transición: era posible utilizar la estructura institucional existente para la misma, abandonando simplemente las prácticas autoritarias (por ejemplo el fraude electoral) que habían operado antes. En 1978, las presiones internacionales llevaron al régimen de Balaguer a abandonar las prácticas fraudulentas que habían posibilitado sus victorias gubernamentales de 1970 y 1974. En Ecuador, donde el orden constitucional preexistente había sido suspendido con la intervención militar, la transición implicaría largas discusiones, que se iniciaron en 1976, entre líderes militares y civiles: sobre la redacción de la constitución, de las leyes referentes al sistema de partidos y de la planeación de las elecciones.

Después de un plebiscito constitucional, de la elección del Congreso y de una elección presidencial de dos vueltas, la transición fue culminada 
con la asunción al poder del presidente Jaime Roldós perteneciente al populista CFP. De cualquier forma, la modernización, llevada a cabo por medios autoritarios, dejaría un legado contradictorio para los regímenes subsecuentes: generaria una burguesía mejor organizada y que buscaría arreglos políticos que dejarían espacio para una representación racional y confiable de sus intereses; pero los gobiernos civiles posteriormente instalados no serían producto de un compromiso de clase; no se basarian en un intento de allanar las relaciones entre el trabajo y el capital, ni comprenderían una transacción que implicara la concesión de derechos políticos y bienestar a las clases populares a cambio de paz social y permanencia del capitalismo. La "democracia" era vista por los sectores empresariales como un medio para reafirmar su influencia en el proceso político. Dados sus derechos limitados para articular sus demandas, las clases populares no eran visualizadas por el sector empresarial como un adversario político amenazante, en consecuencia, la democracia emergería como la alternativa política precisa para un autoritarismo que había pasado su momento floreciente.

Esta ausencia de un compromiso de clase afectó profundamente al comportamiento y desarrollo de partidos, clases y grupos de interés en el periodo postransitorio. Las "normas democráticas" fueron repentinamente impuestas a estos medios peculiares para los que las transiciones se carac. terizaron por la continuidad de los elementos del pasado más que por una discontinuidad marcada de los mismos. Los capitalistas, desencantados de los regímenes autoritarios, estaban listos para renovar sus demandas de manejo de la política económica. Aunque protestaban ocasionalmente, los opositores de las clases populares se mantuvieron divididos y revivieron partidos desorganizados preexistentes, inyectando de nuevo al sistema de partidos sus viejas dinámicas, especialmente el personalismo y el clientelismo. Sin embargo, el rejuvenecimiento de estos actores tradicionales tendría su precio: mientras que el papel dominante de esos participantes conservadores probablemente había facilitado la transición, el peso y las tendencias de comportamiento de estos otros actores les marcarían los límites de la institucionalización de sus procedimientos democráticos dentro del Estado y de sus prácticas democráticas en el cuerpo político.

\section{LA POLÍTICA POSTRANSICIONAL: EL SECTOR EMPRESARIAL Y EL TRABAIO}

Al no representar las clases populares ninguna amenaza significativa, las elites empresariales veían la democracia como un acuerdo institucional al que serían leales sólo si se les abría el acceso a los centros de decisión y a las políticas preferenciales. En consecuencia, ante cualquier "desviación" cuestionaban su apoyo. En Ecuador, la derrota humillante de la derecha en las elecciones presidenciales de 1979 y la victoria de Jaime Roldós 
del partido populista CFP, pusieron a las organizaciones empresariales en alerta, la cual culminó en los ataques beligerantes al siguiente gobierno de Oswaldo Hurtado. ${ }^{10}$ Mientras que Hurtado emprendió políticas que en gran parte favorecieron al sector privado (por ejemplo un programa de estabilización económica moderado, la renegociación de la deuda internacional), su reserva personal y el aislamiento del equipo económico del gobierno creó en el sector privado la impresión de una actitud "antiempresarial" dentro del ejecutivo. ${ }^{11}$. Las cámaras de la industria emprendieron una campaña agresiva en contra del gobierno de Hurtado que llegó a incluir una huelga empresarial de un día demandando su renuncia y, en el caso de la Cámara de la Industria de Guayaquil, un llamado a un golpe de Estado. Sin embargo estas tácticas de desestabilización cesaron cuando se acercaban las elecciones presidenciales de 1984, en medio de expectativas crecientes de una victoria del candidato presidencial del ala derecha y líder empresarial, León Febres-Cordero.

En la República Dominicana, el periodo postransicional se caracterizó por: 1) La consolidación del Consejo Nacional de Hombres de I:mpresa (CNHE) como la organización empresarial más importante; 2) Una intensa politización del CNHE. 3) El control de su consejo ejecutivo por una facción anti-PRD y temerosa del comunismo. Con un creciente número de miembros, el CNHE asumió un papel político directo expresando en términos claros que estaba dispuesto a luchar por la defensa de los intereses empresariales si el gobierno recientemente instalado los llegara a amenazar.

Hubo tres puntos de controversia que enfrentó al CNHE al primer gobierno del PRD, encabezado por el presidente Antonio Guzmán (197882): el CNHE se oponía a las políticas de control de precios, impuestas por el gobierno en un esfuerzo por controlar la inflación; desaprobaba el aislamiento del equipo económico gubernamental con respecto al grupo de presión empresarial y denunciaba la creciente tolerancia hacia la militancia obrera. Los ataques al gobierno se orquestaron a menudo como actos públicos, financiados por el CNHE u organizaciones afiliadas a él. Los eventos de este tipo más publicitados fueron las Cenas Anuales de Empresarios, organizadas por el CNHE. Las de 1979, 1980 y 1981 constituyeron plataformas para duros ataques contra el gobierno. La cúspide del conflicto fue alcanzada en 1980 cuando el equipo económico del gobierno suspendió el diálogo con los representantes empresariales, acerca de la formulación de nuevas políticas económicas, después de

10 El vicepresidente Oswaldo Hurtado asumió la presidencia en mayo de 1981 después de la muerte del presidente Roldós en un accidente aéreo.

il Para una discusion de las tensiones estilísticas entre el gobierno de Hurtado y los grupos empresariales, véase Handelman, "Elite interest", 1985. 
que altos líderes de éstos acusaron al gobierno de irresponsabilidad y de inclinaciones socialistas. Además de sus desacuerdos en materia de política económica, su conflicto se agravó por las consideraciones políticas. la facción pro Balaguer, que controlaba el Consejo Ejecutivo entre 1979 y 1981, tenía un interés estratégico en socavar la administración de Guzmán. En esto existía cierta similitud con la situación en Ecuador, donde los objetivos presidenciales agudizaron los ataques de las organizaciones empresariales al gobierno de Oswaldo Hurtado.

No obstante, en 1982 tuvo lugar un viraje en las relaciones entre gobierno y sector privado en la Dominicana, el cual coincidió con la inauguración del segundo gobierno del PRD encabezado por Salvador Jorge Blanco (1982-86). Estrechando relaciones con empresarios importantes, Jorge Blanco instrumentó gran parte del paquete estabilizador deseado por el sector empresarial y promovido por el Fondo Monetario Internacional (FMI). Aunque algo de austeridad fiscal, desregulación de precios y un tipo de cambio flotante ya habían sido introducidos por el gobierno de Guzmán, con Jorge Blanco se convirtieron en elementos clave del programa oficial. En su discurso inaugural del 16 de agosto de 1982, Jorge Blanco anunció el fin de las políticas keynesianas, favorecidas por su predecesor. Una mayor fluidez de las relaciones entre sector empresarial y gobierno quedó también asegurada con la elección de una facción moderada en el nuevo consejo ejecutivo del CHNE. Éste comprendió que, una declaración de guerra por el sector empresarial al gobierno, aunada a una creciente movilización y descontento populares a causa de las medidas de estabilización, podría llevar a una crisis política de proporciones desconocidas.

De igual manera, un cambio dramático en el tono de las relaciones empresarios-gobierno tuvo lugar en Ecuador con la elección de León Febres-Cordero en 1984. Su posición pro empresarial abierta y la designación de empresarios y tecnócratas conservadores en su gabinete encantó al sector privado. Pero en contraste con las pretensiones de poder de los grupos de presión empresariales bajo la administración anterior, las organizaciones empresariales fueron sorprendentemente mansas con Febres-Cordero. Estaban de acuerdo con la mayoría de las iniciativas mediadoras de la administración, por lo menos, hasta que se agravó la crisis económica en 1987.

El comportamiento de las organizaciones empresariales en el periodo postransicional revela mucho sobre el carácter de estos grupos y de su relación con la democracia. Por un lado, las organizaciones empresariales están dispuestas al juego democrático y a respetar los resultados de las elecciones cuando parecen estar aseguradas las políticas pro empresariales y la contención del sector trabajo; su apoyo a los gobiernos de FebresCordero y de Jorge Blanco ilustra este aspecto. Pero en aquellos 
periodos en que el control y la contención aparecen dudosos, algunas facciones de la burguesía toman la iniciativa y emprenden ataques potencialmente desestabilizadores contra los nuevos y todavía frágiles regímenes democráticos.

Otra característica impactante de las democracias recientemente instaladas en Ecuador y en la República Dominicana es que el movimiento obrero ha sido incapaz de hacer avances significativos o de contrarrestar el poder del sector empresarial. Esto es debido, sin duda, a que tanto el mercado como el sistema político han minado el poder de negociación de los sindicatos. En ambos países, los altos índices de desempleo, el crecimiento del sector informal y la mayor frecuencia de pequeñas y medianas empresas representan obstáculos mayores para el desarrollo de un movimiento sindical fuerte. Otros impedimentos se derivan de las fisuras políticas e ideológicas que aquejan al movimiento obrero y de la falta de compromiso de los partidos políticos hacia la causa laboral.

A pesar de la plataforma pro obrera del Partido Revolucionario Dominicano, los trabajadores tienen pocas ganancias que reportar del gobierno del PRD (1978-89). La inicial agitación obrera que siguió a la instalación del gobierno del PRD en 1978 fue de corta vida y no desembocó en mejores mecanismos de participación. Su fracaso en presentar una posición unificada también dañó la capacidad del sector laboral para obtener concesiones. Mientras el sector empresarial consolidaba sus organizaciones, el movimiento obrero sufría divisiones internas. En consecuencia, en 1986, el movimiento obrero dominicano estaba más fragmentado que nunca. Divisiones con implicaciones políticas en las dos confederaciones laborales más grandes y progresistas, la Central General de Trabajadores (CGT) y la Unión General de Trabajadores Dominicanos (UGTD), debilitaron además al ya dividido movimiento obrero. Hacia mediados de los ochenta, los sindicatos de vieron forzados a adoptar una posición defensiva y lucharon por salarios mínimos más altos que contrarrestaran los efectos graves de las políticas de estabilización y de una inflación galopante. Por otra parte, la envergadura de los saqueos a comercios de 1984 reflejó la ira y la frustración popular causadas por las políticas de ajuste y por la inefectividad de las instituciones y de las organizaciones existentes para articular las demandas populares.

A diferencia de la República Dominicana, el movimiento obrero ecuatoriano dio algunos pasos firmes hacia una mayor unificación a lo largo de la década pasada. En 1975, las tres mayores confederaciones sindicales emprendieron acciones huelguísticas conjuntas y constituyeron una organización dirigente, el Frente Unitario de Trabajadores (FUT). Desde 1979 el FuT auspició once huelgas generales de alcance nacional, sin embargo, el impacto político y económico del sindicalismo quedó limitado en parte, a causa de su diversidad interna. La composición de las 
confederaciones sindicales dentro del FuT abarca una amplia gama, desde los trabajadores rurales pasando por los empleados del servicio público hasta los obreros industriales más tradicionales; en consecuencia, existe una tremenda diversidad tanto en sus condiciones de trabajo como en sus demandas concretas. En estas circunstancias, el fuT funcionó en gran medida como un grupo de presión defensivo y reactivo que visualizó los intereses de los trabajadores en relación con su estatus de consumidores; así fue como el Fut movilizó a sus agremiados para oponerse a las medidas "antipopulares" aplicadas por el gobierno, tales como los incrementos de precios. De esta manera la unidad fraguada por el movimiento obrero fue hecha en relación con un enemigo externo, el gobierno. ${ }^{12}$

Hasta ahora el FUT ha sido incapaz de articular una fórmula alternativa de desarrollo, o sea, un programa coherente que pueda encauzar a los diferentes intereses que representa. Además, la competencia política durante los periodos electorales diluye aun esta unidad "de oposición" en el movimiento obrero, ya que grupos e individuos apoyan a diferentes candidatos. En su gran mayoría, los líderes laborales tienden a constituir un soporte típico de candidatos de la izquierda radical (Frente Amplio de Izquierda, Pratido Socialista, Movimiento Popular Democrático); pero la convocatoria electoral de estos partidos ha sido generalmente muy limitada. Así, los vínculos laborales obreros con la política institucional son débiles y su influencia en los cuerpos de dirección dentro del Estado es marginal.

Mientras que el sector empresarial puede tener siempre una "posición privilegiada" en las democracias capitalistas, como arguyen Charles Lindblom y otros, el poder político y de mercado de este sector con relación al trabajo es más desequilibrado en países como Ecuador y la República Dominicana. ${ }^{13}$ En el periodo postransicional, las organizaciones empresariales se autoproclamaron agresivamente mentores de los responsables de la política económica. Sin embargo, su lealtad a los regímenes democráticos seguía dependiendo de la capacidad gubernamental para mantener el statu quo. Por otra parte, la capacidad del sector laboral para actuar como grupo de presión ha sido limitada por sus propias divisiones internas y porque gran parte de las clases "trabajadoras" en el sector informal de la economía, quedan fuera de las filas del sindicalismo organizado. Dadas estas circunstancias, las demandas y frustraciones populares se expresan de diferente manera. En ambos países, asociaciones de barrio y otras organizaciones de las clases populares han surgido y han formulado demandas muy específicas a los gobiernos locales y nacionales. Pero el problema

12 Para una discusión más amplia del movimiento obrero de Ecuador, véase Jorge León, "Composición social", 1988. Véase tambien Sáinz, Clase obrera, 1985.

13 Para una discusión de la "posición privilegiada" del sector empresarial en sistemas capitalistas avanzados, véase Lindblom, Politics and markets, 1977. 
de estas organizaciones es que no están nucleadas alrededor de objetivos políticos más amplios. Como tales quedan atomizadas y sujetas a control a través del clientelismo. ${ }^{14}$ Los estallidos más amenazantes del descontento popular -saqueos de comercios en la República Dominicana y la emergencia de una guerrilla urbana en Ecuador-provocaron respuestas represivas que ponen en cuestión la integridad del régimen democrático.

\section{EL DESORGANIZANTE SISTEMA DE PAR'TIDOS}

Como muestra nuestra discusión, factores estructurales (como por ejemplo una extrema heterogeneidad social, el patrón de crecimiento económico y los efectos de la crisis económica) inhibieron el desarrollo de organizaciones de clase baja que fueran capaces de actuar como contrapesos efectivos del poder del grupo de presión empresarial. Este fracaso se extiende hasta el sistema de partidos. Hasta ahora, los partidos han sido incapaces de actuar como productores de un consenso que abarcara a toda la sociedad con respecto al desarrollo económico capitalista y a la democracia.

Crisis de representación y de racionalidad están en la raíz de los problemas en el interior del sistema de partidos. Los partidos adolecen de tener vínculos débiles con grupos de la sociedad civil y las elites políticas, de incapacidad para liberarse de los métodos tradicionales de hacer política que se caracterizan por usar del personalismo, el clientelismo y el faccionalismo. Ambos problemas contribuyen a aumentar las tendencias centrífugas y antiorganizativas dentro del sistema de partidos. La crisis económica agrava la lucha entre las elites políticas por el control de recursos y patrocinadores; a veces lleva a los partidos gobernantes a abandonar sus compromisos electorales reformistas, lo que da lugar a serios cuestionamientos en cuanto a la responsabilidad de las instituciones democráticas.

Como anotamos más arriba, los partidos ecuatorianos cristalizaron en un ambiente desfavorable al desarrollo de fuertes partidos populares. Restricciones al sufragio, dominación oligárquica e intervención militar fueron los factores que se conjugaron para inhibir el desarrollo partidario. El desprecio hacia los partidos, demostrado por lideres como José María Velasco Ibarra, permeaba el discurso político ecuatoriano. Los partidos nunca adquirieron un prestigio heroico como protagonistas de la democratización, como el del APRA de Perú, la Acción Democrática de Venezuela y el Partido Revolucionario Dominicano. Los vínculos afectivos con la organización partidaria entre los activistas, así como la importancia del puesto y curriculum dentro del partido eran débiles, de manera que

14 Lesser, Conflicto y poder, 1987. 
la competencia por los puestos directivos y las nominaciones partidarias fácilmente dieron lugar a divisiones y a la creación de partidos de escisión.

Las tendencias centrífugas y antiorganizativas en el sistema de partidos ecuatoriano se vieron reforzadas por algunas de las disposiciones en la nueva ley de regulación partidaria. La Ley de Partidos, adoptada durante el proceso de transición en 1978, facultó al Tribunal Supremo Electoral para limitar el número de partidos a través de los procedimientos de licencia y de la obligación de los candidatos potenciales de afiliarse a partidos legalmente registrados. En teoría, el Tribunal podía usar sus poderes para eliminar partidos pequeños de la escena electoral y para limitar la proliferación de los mismos. En la práctica, el intento de condensar y racionalizar el sistema de partidos a través de los medios jurídicos no fue del todo exitoso. El Tribunal mismo era renuente a provocar controversias eliminando partidos pequeños del registro electoral. Y la disposición que exigía a los candidatos a puestos públicos vincularse a partidos legalmente registrados, "obligaba" a muchos de los que buscaban hacer carrera política a establecer uniones artificiales y oportunistas. La debilidad de estos vínculos se reflejaba en un fenómeno conocido como cambio de camiseta, esto es, la deserción frecuente de miembros del Congreso de sus respectivos partidos. Dada una lealtad partidaria tan débilmente cimentada, las afiliaciones partidarias se cambiaban fácilmente, de acuerdo con las ventajas relativas que los miembros del Congreso calculaban obtener de diferentes patrocinadores para su suerte electoral futura.

Esta falta de compromiso partidario y la impredictibilidad que ello generaba, tenía repercusiones en todas las dimensiones de la política en Ecuador, desde los resultados electorales hasta el carácter de las relaciones intergubernamentales. La lucha por el liderazgo en el CFP dividió a la mayoría gubernamental en el Congreso y creó un conflicto crónico entre el ejecutivo y el legislativo durante el gobierno del presidente Jaime Roldós y de su sucesor Osvaldo Hurtado.

Conflictos abiertos entre el Congreso y el presidente marcaron la administración de Febres-Cordero de 1984 a 1988. El abierto desdén de Febres-Cordero hacia los partidos lo llevó a tratar de erosionar la mayoría centroizquierdista en el legislativo a través de amenazas y sobornos. Esto incrementó los enfrentamientos entre el presidente y el Congreso. La posibilidad de una "ruptura" en los nuevos acuerdos institucionales fue recurrente durante la administración de Febres-Cordero a causa de estas batallas desestabilizadoras entre el ejecutivo y el legislativo. La mayor parte de las cuestiones de procedimiento que se hallaban en la raíz de los conflictos y nunca se "resolvieron", simplemente se desvanecieron. El presidente ignoraba por rutina las acciones del Congreso, creando un ambiente legal extremadamente obscuro. ${ }^{15}$

15 El rechazo de Febres-Cordero a reconocer la amnistía declarada por el Congreso para 


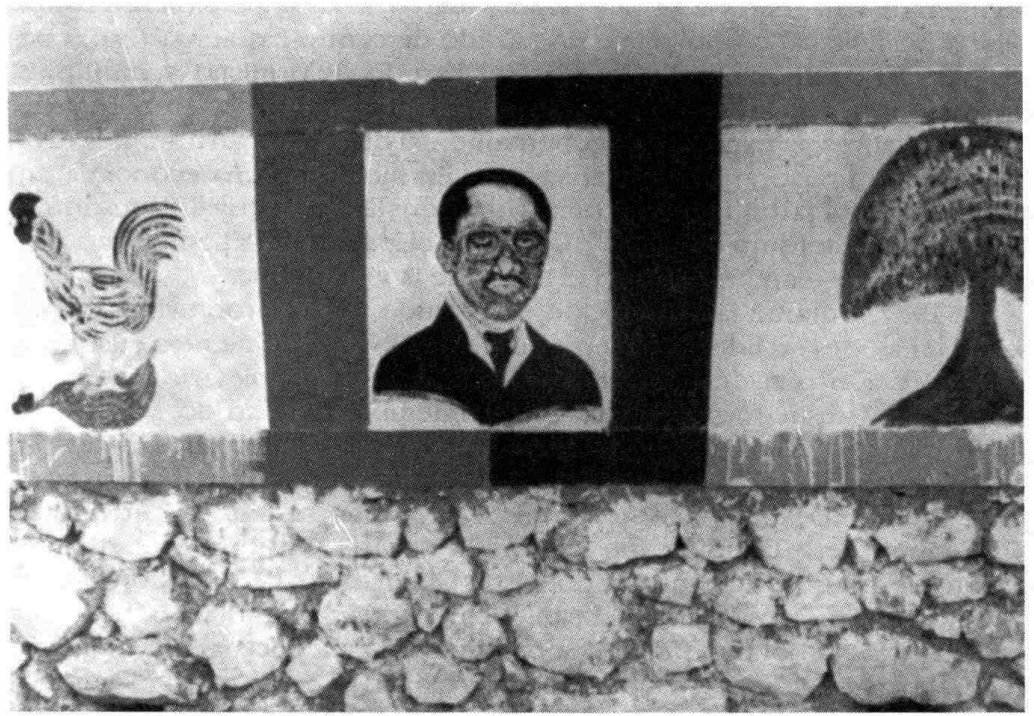

A diferencia del Ecuador, las condiciones para el desarrollo de partidos de masas eran más favorables en la República Dominicana. Después del asesinato de Trujillo, y una vez desmantelado el Partido Dominicano, se formaron varios partidos políticos y se instituyeron las prerrogativas democráticas básicas. Y tras una aguda competencia por el voto popular a principios de los sesenta, el Partido Revolucionario Dominicano (PRD) emergió como partido democrático de masas. Los trágicos sucesos que se iniciaron con el derrocamiento de Juan Bosch en 1963, la guerra civil de 1965 y la subsecuente intervención estadunidense contribuyeron a consolidar la imagen heroica del PRD como protagonista de la democratización. Esta imagen se reafirmó durante el régimen de Balaguer, en que el PRD sufrió persecuciones y derrotas, pero éste se mostró finalmente capaz de reorganizarse y de desafiar a Balaguer en la arena electoral. Hacia 1978 había dos partidos dominantes: el Partido Reformista de Balaguer y el PRD. Ambos totalizaron el 95\% de los votos en las elecciones de 1978. El PRD encabezó la votación con el $51.9 \%$ de los sufragios. El colapso y la subsecuente crisis del

el general disidente Frank Vargas Pazzos, precipitó su secuestro por contingentes de la fuerza aérea en enero de 1987. 
régimen de Balaguer y la amplia popularidad del PRD se percibieron como signos positivos al consolidarse un partido de centro-izquierda (PRD) con un partido debilitado a la derecha (el Partido Reformista) y múltiples organizaciones más pequeñas a la izquierda. Sin embargo, en contra de las expectativas, la experiencia gubernamental del PRD mostró ser negativa para su maduración como organización. En medio de una economía en declive, lo aquejaron factores como el personalismo, las rivalidades intraelite y el clientelismo "abusivo". Como en el pasado, el clientelismo y la corrupción seguían permeando el tejido de la vida política.

En 1977, durante la convención del partido, se hicieron evidentes las serias tensiones de liderazgo dentro del PRD. Dos contendientes buscaban la nominación presidencial: Antonio Guzmán, un propietario de tierras moderado y desde hacía mucho tiempo miembro del partido, y Salvador Jorge Blanco, un abogado liberal y defensor de los derechos civiles. A pesar de la oposición del ala izquierda del partido, Guzmán derrotó a Jorge Blanco. Después de este conflicto el partido se unió para derrotar a Balaguer, pero la unión fue de corta vida. Las tensiones resurgieron pronto después de la toma del poder de Guzmán en 1978. Las presiones que ejercieron otros líderes del PRD, incluyendo a Jorge Blanco, tuvieron importancia simbólica y práctica sobre Guzmán que declaró una amnistía general para beneficiar a los prisioneros y exiliados políticos. Esto ayudó a consolidar la imagen de Jorge Blanco como político progresista. En' un esfuerzo por ganar apoyo entre los seguidores del PRD, Jorge Blanco emprendió una campaña en contra de Guzmán por rechazar éste la supresión de la reelección y por excluir a cuadros del partido de la administración pública. Ambos puntos atrajeron a los militantes del PRD. Finalmente, tensiones severas y controversias sobre prácticas clientelistas dañaron seriamente las relaciones partido-gobierno. En el contexto de una economía en deterioro, con manifestaciones populares en auge y frente a una comunidad empresarial crecientemente politizada, el faccionalismo intrapartidario dificultaba la tarea de gobernar. El gobierno se tambaleaba de crisis en crisis, y desembocó en el suicidio de Guzmán en julio de 1982. Ocurrió poco antes de la investidura de Salvador Jorge Blanco como nuevo presidente electo del PRD.

En contra de muchas predicciones, Jorge Blanco no cumplió sus promesas electorales. Desde el inicio, el gobierno aplicó las políticas de estabilización del FMI que implicaban devaluaciones drásticas del peso dominicano, austeridad fiscal y control de precios. El discurso inaugural de Jorge Blanco del 16 de agosto de 1982 reflejó más la política ortodoxa de fines de los sesenta que la plataforma del PRD progresista. El énfasis estaba puesto en la austeridad y no en la redistribución, en las restricciones y no en las concesiones. Las crecientes dificultades económicas aunadas a la corrupción y a un clientelismo "altamente selectivo" por parte del 
gobierno (por ejemplo, se otorgaban privilegios a algunos individuos para importar bienes de lujo inaccesibles a las clases medias y altas) agravaron el descontento del pueblo.

Con tal administración de Blanco y la destrucción del partido por rivalidades internas, la Convención de 1985 desembocó en una división de facto. Al contar los votos, estalló la violencia. Se reportó ampliamente que el asalto había sido perpetrado por seguidores de Jorge Blanco que aparentemente intentaban evitar la victoria de su oponente, Jacobo Majluta. La crisis del partido quedó temporalmente resuelta con el acuerdo (el Pacto La Unión) de no tomar en cuenta los votos de los delegados de la convención. Se concedió a Majluta la nominación como candidato presidencial del PRD en 1986, mientras que se aseguraron a la facción de Jorge Blanco nominaciones claves para el Congreso. No obstante, con un candidato débil y un partido dividido, el PRD perdió las elecciones de 1986 ante Balaguer.

Los sucesos alrededor de la Convención de 1985 son indicativcs de los problemas profundamente arraigados en el sistema de partid os dominicano. Primero, parece poco probable que el PRD se desembarazara suficientemente rápido del faccionalismo intrapartidario y, de hecho, una división formal no puede descartarse. Segundo, pese a algunos esfuerzos menores para modernizarse y democratizarse, el Partido Reformista de Balaguer (con su nuevo nombre de Partido Reformista Socialcristiano) sigue siendo una organización personalista y clientelista, con pocas probabilidades de sobrevivir intacta a la muerte de Balaguer. Finalmente, el Partido de Liberación Dominicano (PLD) de Juan Bosch, que ha hecho avances significativos desde 1978, también es una organización sujeta a cambios importantes después de la muerte de Bosch.

Tendencias centrifugas minan la estabilidad de un sistema de partidos que fue crucial en la transición dominicana de 1978. Es importante subrayar que en medio de condiciones socioeconómicas adversas, el PRD desempeñó un papel central en la articulación de los ideales políticos al canalizar la participación política y al mantener a los militares fuera de la misma. Con la fragmentación partidaria y un probable reagrupamiento, parece poco claro cómo pueden exactamente articularse las demandas populares dentro de las estructuras institucionales, dado el estado precario de otras organizaciones sociales. Además, la severidad de la crisis se aúna a la dificultad de desarrollar arreglos corporativos de integración.

\section{CONCLUSIÓN}

Ha pasado más de una década desde que la República Dominicana y Ecuador emprendieron transiciones a la democracia, pero la "normalidad" todavía no se ha convertido en una característica de la vida política. Se 
alcanzó la rotación electoral, pero las interrupciones periódicas de los procedimientos y prácticas democráticos todavía ocurren, especialmente en la solución de conflictos institucionales y en la toma de decisiones. Atrás de la fachada de una política democrática, permanece un mundo de maniobras extra institucionales e ilegales.

El desarrollo socioeconómico de estos países en el siglo xx no ha creado la base para algún tipo de consenso entre las clases sobre democracia y capitalismo. Las exportaciones, basadas en la agricultura y una industrialización estancada, produjeron una clase obrera relativamente pequeña y un estrato grande y desorganizado de trabajadores informales y campesinos. Diferencias étnicas y linguísticas fragmentaron además a los grupos de las clases bajas. Dadas estas divisiones, el movimiento sindical nunca emergió como el interlocutor más importante de las clases bajas. La debilidad de sus organizaciones significó que existían pocas bases para contrarrestar el poder de las clases dominantes. Desde la perspectiva de las elites empresariales, una mejor distribución de los recursos económicos no era crucial para la conservación del orden capitalista. Lo que era crucial según ellas, era el acceso al Estado para la obtención de políticas favorables. Cuando los regímenes autoritarios se mostraron impredecibles en su distribución de favores y acceso, las elites empresariales se unieron a los clamores de una transición democrática. El retorno a la democracia, sin embargo, no se vio acompañado por un consenso sobre la política económica. Las elites se mantenían listas para abandonar el juego democrático normal cuando sus resultados les parecieran desfavorables para ellas. Este submundo no democrático está enraizado en la ausencia de un compromiso de clase y de un entendimiento durable entre las elites. Un abismo profundo separa el capital del trabajo, abismo que es a la vez económico y político; las concesiones económicas a los obreros han sido mínimas desde la transición y no ha emergido un nuevo mecanismo de solución de conflictos. Además, como la democratización coincidió con la crisis de la deuda de los ochenta, las lealtades de masas al nuevo régimen no han sido cimentadas con recompensas económicas.

Los políticos profesionales han hecho poco para unir a los grupos dispersos de estas sociedades, ni siquiera han asegurado entre ellos algún acuerdo sobre las reglas básicas precisas para el sistema democrático. Los partidos exhiben extremos de clientelismo y personalismo, que los exponen a la fragmentación y a la disolución. El estado débil e impredecible del sistema de partidos es un factor importante que contribuye al ambiente de inestabilidad.

Los sistemas políticos que emergieron en la República Dominicana y Ecuador reflejan lo que Przeworski y Wallerstein denominan el "empate inestable" que ocurre en ausencia de un compromiso de clase. Sin embargo, debemos cuidarnos de concluir que este empate necesariamente 
llevará a una ruptura en estos regímenes. Ciertamente, una quiebra de la democracia permanece como posibilidad real, pero la manera en que estos sistemas han avanzado en medio de crisis políticas, económicas y constitucionales durante la década pasada, sugiere una enorme capacidad para "salir del paso". ${ }^{16}$ En lugar de encaminarse hacia otra ronda de quiebras (del estilo descrito por Juan Linz) posiblemente presenciaremos la evolución de una nueva variante del régimen, una "democracia con tendencia a la crisis". ${ }^{17}$

En la década de los setenta, surgieron en el Cono Sur, regímenes burocrático-autoritarios que trataban de aislar la política económica de las presiones sociales; una parte del proceso implicaba una desmovilización forzada de las previamente activadas clases populares. Amenazada por las demandas de éstas, la alta burguesía apoyó al régimen autoritario y sus intentos de normalización económica. ${ }^{18}$ En la República Dominicana y Ecuador la búsqueda de esta burguesía de un nuevo (y más predecible) acceso al Estado facilitó la transición política a la democracia. Por el contrario, las experiencias del Cono Sur fueron negativas: la represión sistemática fue un procedimiento capital en la restauración de las relaciones entre el sector empresarial y el Estado, y la desorganización de las clases bajas y el sistema de partidos, efectivamente socavó la capacidad de estos actores para plantear al sistema demandas reformistas o redistributivas, a finales de los setenta. En la República Dominicana y Ecuador, la "reconquista" del poder político por la burguesía era compatible con la solicitud de votos y la competencia política, ya que la amenaza popular había permanecido relativamente reducida. Pero aun en esta ausencia de amenaza sustancial, no se afinaron las instituciones democráticas para proveer la predictibilidad que originalmente la burguesía había buscado. Además, los políticos se habían aferrado a formas irregulares e impredecibles de solución de conflictos que incluían hasta arreglos entre bambalinas de uso de la fuerza física. De esta manera, un juego enredado de elementos institucionales y extrainstitucionales seguía siendo parte del tejido de estos regimenes políticos híbridos.

\section{BiBLIOGRAFÍA}

-Conaghan, Catherine M., Restructuring domination: industrialists and the State in Ecuador, Pittsburgh, 1988.

-Dahl, Robert, Polyarchy: participation and opposition, New Haven, Connec. ticut, 1971.

16 Esta referencia es de la obra clásica de Charles Lindblom sobre crecimiento en el proceso políico, véase "The science", 1969, pp. 166-170.

17 Para la descripción clásica de Juan linz de cómo quiebran las democracias, véase su "Crisis, breakdown", en Linz, The breakdown, 1978.

18 Para el análisis más reciente, véase O'Donnell, "Burocratic-Authoritarianism", 1988. 
-Espinal, Rosario, "Classes, power and political change in the Dominican Republic", tesis de doctorado en filosofia, Washington University, 1985.

-Espinal, Rosario, Autoritarismo y democracia en la política dominicana, San José, 1987.

-Gleijeses, Piero, The dominican crisis, Baltimore, 1978.

-Handelman, Howard, "Elite interest groups under military and democratic regimes: Ecuador, 1972-1984", ponencia presentada en el XII Congreso International, Latin American Studies Association, Albuquerque, Nuevo México, abril de 1985.

-Herman, Edward y Frank Broadhead, Demostration elections: U. S.-Staged elections in the Dominican Republic, Vietnam, and El Salvador, Boston, 1984.

-León, Jorge, "Composición social y escena política en el sindicalismo ecuatoriano", ponencia presentada en el XIV Congreso Internacional, Latin American Studies Association, Nueva Orleáns, marzo de 1988.

-Lesser, Mishy, Conflicto y poder en un barrio popular de Quito, Quito, 1987.

-Lindblom, Charles, "The science of 'Muddling Through'", en Amitai Etzioni (comp.), Readings in modern organizations, Englewood Cliffs, New Jersey, 1969.

-Lindblom, Charles, Politics and markets: the world's political economic systems, Nueva York, 1977.

-Linz, Juan, "Crisis, breakdown, reequilibration" en Juan Linz y Alfred Stepan (comps.), The breakdou'n of democratic regimes, Baltimore, 1978.

-Middleton, Alan, "Division and cohesion in the working class: artisans and wage labourers in Ecuador", Journal of Latin American Studies, vol. XIV núm. 1, 1982, pp. 171-197.

-Moore, Barrington, Jr., Social origins of dictatorship and democracy: lord and peasant in the making of the modern world, Boston, 1966.

-O'Donell, Guillermo y Philippe Schmitter, Transitions from autboritarian rule: tentative conclusions about uncertain democracies, Baltimore, 1988.

O'Donell, Guillermo, "Burocratic-Authoritarianism: Argentina, 1966-1973", en Comparative Perspective, trad. James McGuire, Berkeley, 1988.

-O'Donell, Guillermo, Philippe Schmitter y Laurence Whitehead (comps.), Transitions from autboritarian rule: Latin America, Baltimore, 1986.

-Pérez Sáinz, Juan Pablo, Clase obrera y democracia en Ecuador, Quito, 1985.

-Prseworski, Adam, Capitalism and social democracy, Cambridge, 1985.

-, y Michael Wallerstein, "The structure of class conflict in democratic capitalist societies", American Political Science Review, vol. LXXVI núm. 76, 1982.

-skocpol, Theda, State and social revolutions: a comparative analysis of France, Russia, and Cbina, Cambridge, 1979.

-United Nations Economic Commissions for Latin America, Statistical yearbook for Latin America, Nueva York, 1981. 